\title{
USO DA CARTA GEOTÉCNICA NO MACROZONEAMENTO DO LITORAL NORTE, SÃO PAULO
}

\author{
Álvaro Gutierrez LOPEZ \\ Carlos Geraldo Luz de FREITAS \\ Mariângela BARROS \\ Sidnei Tadeu RODRIGUES
}

\begin{abstract}
RESUMO
Através da utilização da Carta Geotécnica do Litoral Norte, em São Paulo, foram definidas, para o macrozoneamento, quatro classes de aptidão à ocupação, com vistas ao planejamento regional, nas quais são descritas as principais características físicas e geotécnicas e seus problemas relativos aos vários tipos de ocupação antrópica. Como resultado obteve-se um mapa onde estas 4 classes são cartografadas e anexou-se uma tabela onde se propõe a forma mais correta de uso dos espaços. A compilação cartográfica é feita através do sistema geográfico de informações (SGI).
\end{abstract}

\section{ABSTRACT}

Four classes of land use were defined in the northern coast of São Paulo, for use in regional planning. The main physical and geotechnical characteristics are described, as well as problems related to human occupation. A map showing the four classes and a table for adequate use of space are presented. Mapping was effected by means of SGI.

\section{INTRODUÇÃO}

O macrozoneamento do litoral norte de São Paulo é um projeto sob a responsabilidade da Secretaria Estadual do Meio Ambiente de São Paulo (SMA) e tem como objetivo propor a ordenação do uso e ocupação do solo, bem como seus limites, através de um planejamento ambiental, de forma a definir atributos geotécnicos, legais, características de vegetação e paisagísticas, essenciais e específicas a serem buscadas com esse fim. O produto básico do macrozoneamento será o instrumento que subsidiará o gerenciamento costeiro a ser aplicado na região, que abrange os cinco municípios do litoral norte, a saber: Bertioga, São Sebastião, Caraguatatuba, Ilhabela e Ubatuba, como pode ser observado na figura 1 - Mapa de localização da área de estudo. A carta geotécnica, utilizada como um dos instrumentos de planejamento regional, aborda os atributos do meio físico, quanto à forma mais adequada à sua ocupação, e apresenta diretrizes que possibilitem ações efetivas e corretas, do ponto de vista ambiental, para esta ocupação.

\section{MATERIAL E MÉTODOS}

Basicamente, para este trabalho, utilizouse a carta geotécnica do litoral norte, para o agrupamento das classes de aptidão, e o sistema de informações geo-referenciadas (SGI), VERSÃO 150-SITIM/SGI-ENGESPAÇO/FUNCATE, para os cruzamentos de dados e produções cartográficas. A escala final dos mapas é em 1:50.000; porém, com a utilização do SGI, tais mapas foram reduzidos neste trabalho a 1:100.000, mantendo, contudo, por questões estéticas, a densidade de informação da escala inicial (1:50.000). A seguir, é examinada e discutida a carta geotécnica elaborada anteriormente, de modo a estabelecer critérios de sistematização dos parâmetros geotécnicos existentes e detectar os dados complementares necessários.

\subsection{Carta geotécnica do litoral norte}

A carta geotécnica do litoral norte é composta por 14 folhas 1:50.000, cartografadas também pelo SGI, VERSÃO 150-SITIM/SGIENGESPAÇO/FUNCATE, abrangendo os cinco municípios do litoral citados anterior- 


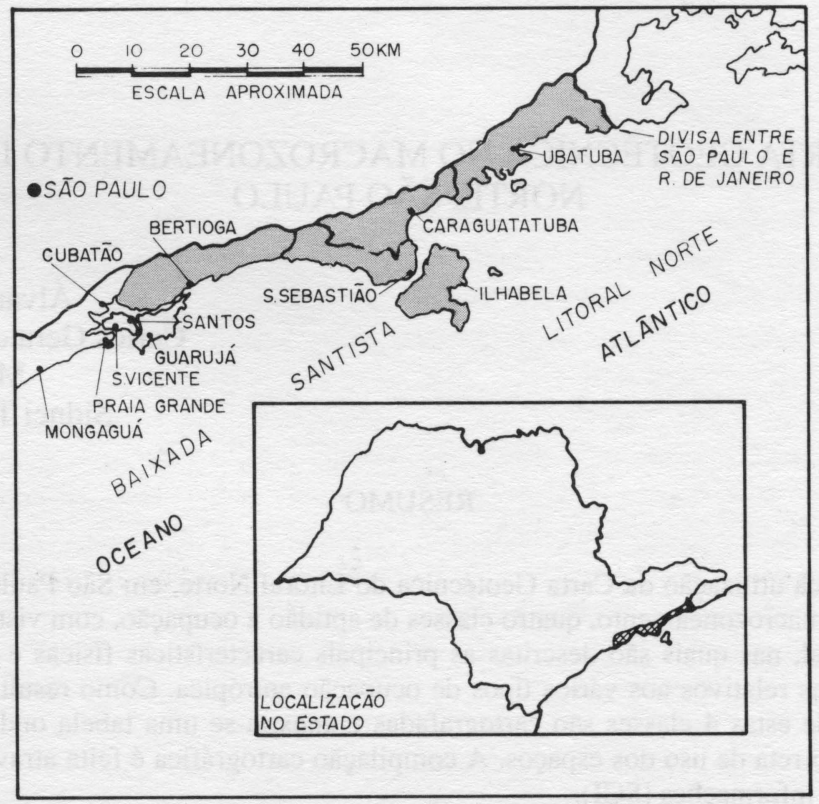

FIGURA 1 - Mapa de Localização.

mente. Para um melhor entendimento da metodologia utilizada para a confecção da carta, deve-se inicialmente compreender que o litoral norte pode, numa forma simplificada, ser dividido em dois grandes compartimentos - encostas e planícies, com uma zona de transição entre estes compartimentos, como pode ser observado no perfil esquemático a seguir (Fig. 2 - Perfil esquemático).

Relativos a tais compartimentos, encontramos problemas específicos que condicionam ou restringem a ocupação, como: nas`encostas, escorregamentos, blocos rolados, corridas de massa, processos erosivos, recalques diferenciais, declividades acentuadas e relacionadas às planícies, como: enchentes, alagamentos, assoreamentos, recalques por argila, dificuldades de drenagem e saneamento básico.

Esses problemas estão intrinsecamente ligados à evolução de processos naturais como chuva, erosão fluvial e marinha - e condicionados por características do meio físico, como tipos de solos, posição geomorfológica de depósitos, a gênese dos terrenos etc. Os processos naturais e seus parâmetros são modificados por atividades antrópicas como mineração, abertura de loteamentos, ocupação inadequada de várzeas ou encostas, disposição inadequada de rejeitos, má condução de águas pluviais, esgotos etc.
Esses processos naturais ou induzidos geram inaptidões à ocupação ou potencializam situações de risco. Portanto, a metodologia empregada na confecção da carta foi o entendimento fenomenológico dos processos, com base na verificação dos problemas à ocupação. Como resultado, temos a definição de unidades geotecnicamente homogêneas, ou seja, um mapa, como mostrado a título de exemplo na figura 3 - Representação vetorial das unidades geotécnicas -, trecho da Folha Bertioga, cuja legenda é mostrada na tabela 1 , onde os compartimentos são definidos pelas suas características e demarcados pelas unidades geotécnicas, através da numeração correspondente a cada unidade. Deve ser alertado o fato de que as unidades referentes à dinâmica marinha (unidades 1,2 e 3 ) bem como a unidade 19 , relativa às corridas de massa, encontram-se em fase de término da cartografia, o que será concluído num futuro próximo; porém, sem comprometer os resultados obtidos, uma vez que tais processos foram levados em conta para a análise final. Os traços verticais (N-S), vistos no mapa, podem ser desconsiderados, uma vez que são decorrentes da redução e impressão do mapa original. 


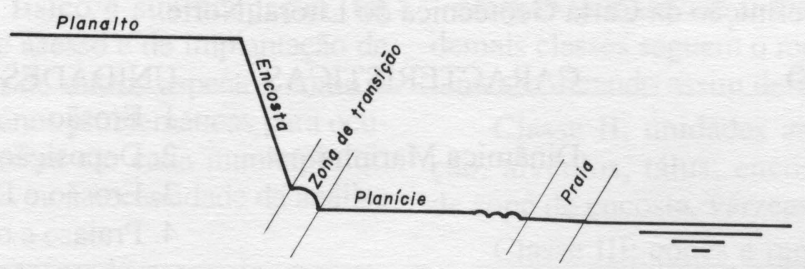

FIGURA 2 - Perfil Esquemático.
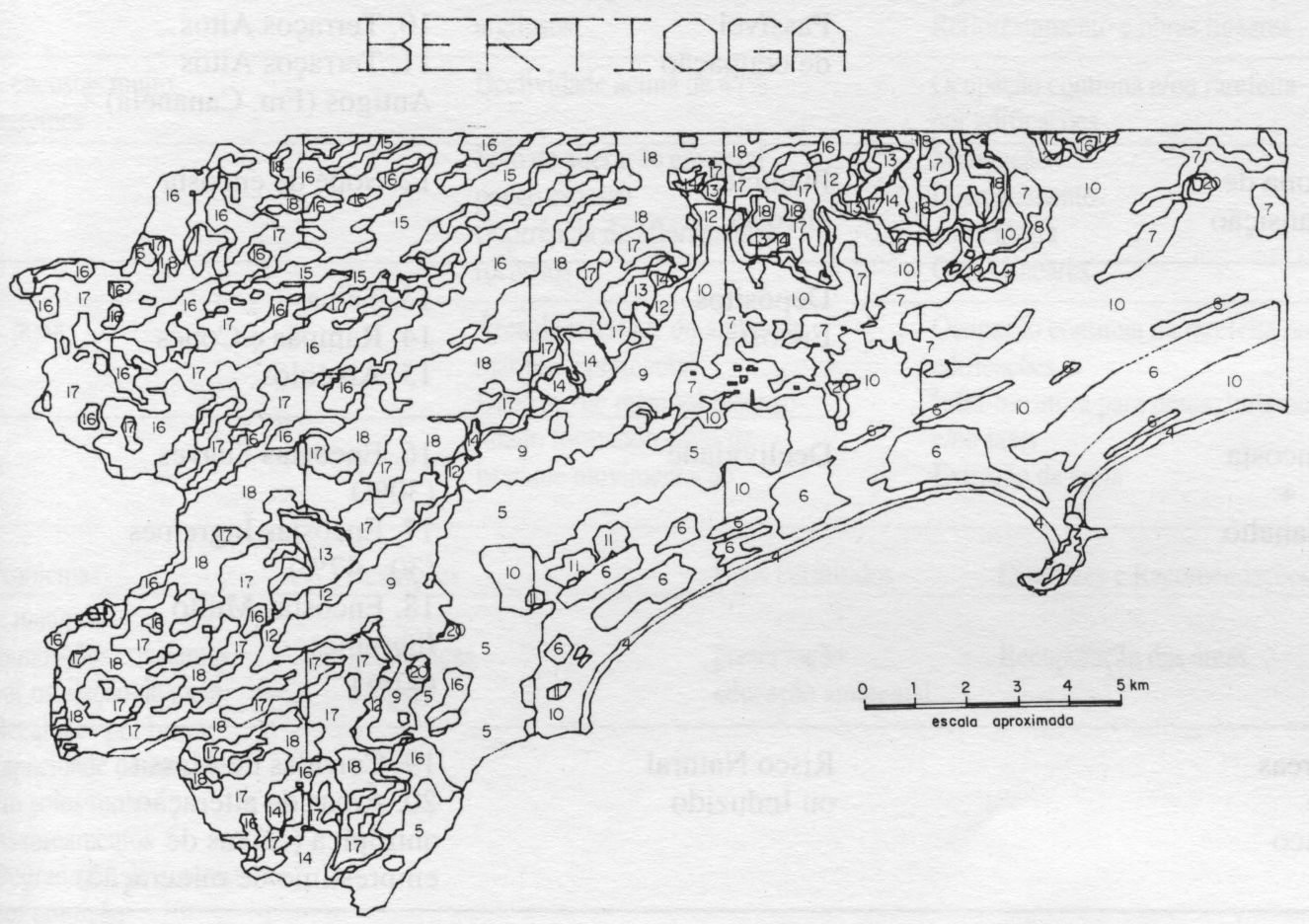

FIGURA 3 - Representação vetorial das unidades geotécnicas - Trecho Folha Bertioga (Legenda na Tabela 1).

\section{RESULTADOS}

Como se pode observar na tabela 1 , as unidades geotécnicas consideradas são representati- vas para todo o litoral norte, mas variam de folha para folha, ou seja, dependendo da região analisada podemos ter uma parte ou a totalidade dessas unidades. Para o macrozoneamento, 
TABELA 1 - Definição da Carta Geotécnica do Litoral Norte.

\begin{tabular}{lll} 
COMPARTIMENTO & CARACTERÍSTICAS & UNIDADES GEOTÉCNICAS \\
\hline \multirow{2}{*}{ Linha Costa } & Dinâmica Marinha & 1. Erosão \\
& & 2. Deposição \\
& & 3. Erosão e Deposição \\
& & 4. Praia
\end{tabular}

5. Mangue

6. Zonas Intercordões

7. Alagadiços (brejos, várzeas e

Inundação e

Recalque

planícies de

inundação)

8. Zonas Alagáveis por

ação antrópica

Planície

(minerária)

9. Zonas Paleolagunares

Paleomangue Bertioga

Passível 10. Terraços Altos

de ocupação 11. Terraços Altos

Antigos (Fm. Cananéia)

\begin{tabular}{lll}
\hline $\begin{array}{l}\text { Zona de } \\
\text { transição }\end{array}$ & $\begin{array}{l}\text { Planície/ } \\
\text { encosta }\end{array}$ & 12. Sopé de encosta
\end{tabular}

\begin{tabular}{|c|c|c|}
\hline & $\begin{array}{l}\text { Depósitos } \\
\text { Encosta }\end{array}$ & $\begin{array}{l}\text { 13. Tálus } \\
\text { 14. Rampas e Cones } \\
\text { 15. Alvéolos }\end{array}$ \\
\hline $\begin{array}{l}\text { Encosta } \\
+ \\
\text { Planalto }\end{array}$ & Declividade & $\begin{array}{l}\text { 16. Encostas Suaves } \\
(30 \%) \\
17 . \text { Encostas Íngremes } \\
(30-47 \%) \\
18 . \text { Encostas Muito } \\
\text { Íngremes } \\
(47 \%)\end{array}$ \\
\hline $\begin{array}{l}\text { Áreas } \\
\text { de } \\
\text { risco }\end{array}$ & $\begin{array}{l}\text { Risco Natural } \\
\text { ou Induzido }\end{array}$ & $\begin{array}{l}\text { 19. Corridas de Massa } \\
\text { 20. Áreas de alteração } \\
\text { antrópica (caixas de } \\
\text { empréstimo de mineração) }\end{array}$ \\
\hline
\end{tabular}

foram analisados e reagrupados os compartimentos da Carta Geotécnica em quatro conjuntos de unidades do terreno, segundo o grau de fragilidade ante a ocupação e, portanto, com diferentes restrições e diretrizes correspondentes. As quatro classes de aptidão à ocupação assim definidas foram:

Classe I - Áreas extremamente susceptíveis a impacto;

Classe II - Áreas muito susceptíveis a impacto;

Classe III - Áreas mediamente susceptíveis a impacto; $\mathrm{e}$

Classe IV - Áreas pouco susceptíveis a impacto.
Cada unidade foi caracterizada do ponto de vista dos seus principais processos, naturais ou induzidos, e suas características geotécnicas de interesse. Posteriormente, foram assinalados os conflitos e problemas existentes ou possíveis de acontecer, resultantes da ocupação dessas unidades. Tais dados foram dispostos em forma de tabela, e as unidades, delimitadas, cartograficamente.

A incorporação de compartimentos geotécnicos de fragilidade diferenciada em uma mesma unidade foi, eventualmente, necessária devido à escala e ao objetivo do macrozoneamento. Os critérios estabelecidos para essas situações levaram em conta outros fatores para o entendimento 
integrado do meio físico e sua ocupação, tal como a facilidade de acesso e de implantação de infra-estrutura, além de outros aspectos como a extensão de áreas menos problemáticas para ocupação urbana, existentes em cada município do litoral norte, o que levou à necessidade de análise dessas situações caso a caso.

A tabela 2, apresentada a seguir, mostra, como exemplo, a Classe I de aptidão à ocupação
- áreas extremamente susceptíveis a impacto:As demais classes seguem o mesmo padrão de tabelamento, ficando assim definidas:

Classe II: unidades antrópicas de mineração, alvéolos, tálus, encostas íngremes, faixa de sopé de encosta, várzeas e brejos.

Classe III: cones e rampas, terraços paleolagunares, cordões e intercordões.

Classe IV: encostas suaves e terraços.

TABELA 2 - Classe I de aptidão à ocupação.

$\begin{array}{lll}\text { Classes de Aptidão } & \text { Características Físicas } & \text { Usos Geradores de Possíveis } \\ \text { à Ocupação } & \text { Conflitos }\end{array}$

\section{Áreas extremamente susceptíveis a impacto}

$\begin{array}{lll}\text { a. mangue } & \text { Terrenos baixos e planos } & \text { Ocupação contínua e/ou rarefeita } \\ \text { situados ao nível de oscilações } & \text { Extrativismo } \\ \text { da maré. Sedimentos orgânicos e } & \text { Agricultura } \\ \text { argilosos. } & \text { Reflorestamento e obras lineares }\end{array}$

\begin{tabular}{lll}
\hline $\begin{array}{l}\text { b. encostas muito } \\
\text { íngremes }\end{array}$ & Declividade acima de 47\% & $\begin{array}{l}\text { Ocupação contínua e/ou rarefeita } \\
\text { por edificações }\end{array}$ \\
& Solo de alteração em geral & Mineração \\
& pouco espesso & Desmatamento \\
& Ocorrência de afloramentos & Agricultura \\
& rochosos & Obras lineares \\
\hline c. praia & Área de interface do ambiente & Ocupação contínua ou rarefeita por \\
& marinho/continental & edificações \\
& Depósito de material inconso- & Infra-estrutura para pesca, turismo \\
& lidado formando áreas de & e/ou lazer \\
& bastante movimentação & Extração de areia
\end{tabular}

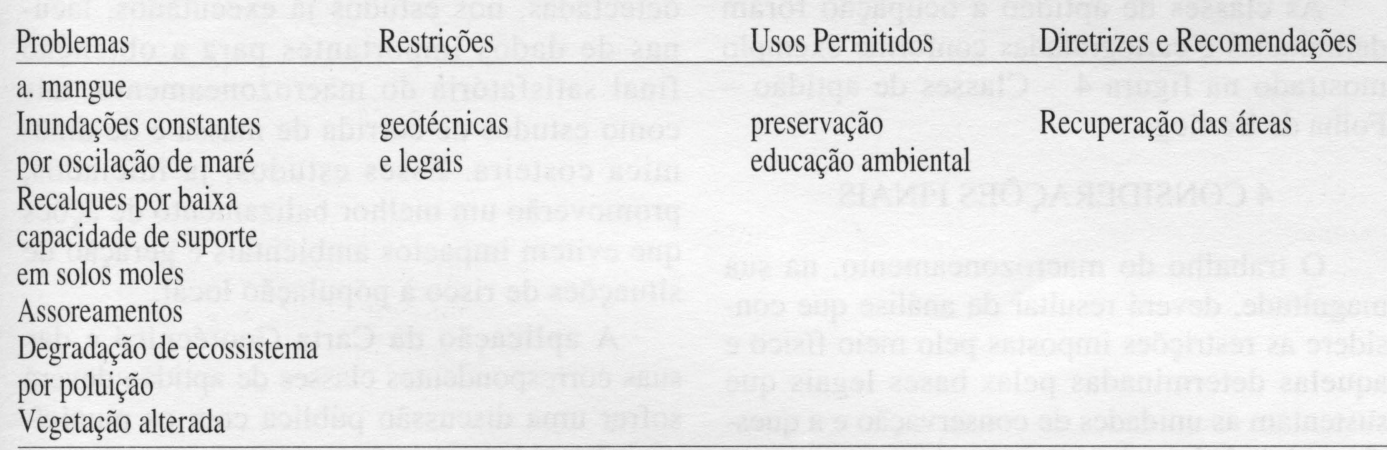

b. encostas muito íngremes

Escorregamentos ou queda de blocos natural ou induzida, afetando áreas adjacentes, podendo fornecer material para eventuais corridas de massa

$\begin{array}{lll}\begin{array}{l}\text { Implantação de } \\ \text { edificações, mi- } \\ \text { neração e ativi- } \\ \text { dades agropasto- } \\ \text { ris }\end{array} & \begin{array}{l}\text { Preservação } \\ \text { Ecoturismo } \\ \text { Obras lineares } \\ \text { Reflorestamento em } \\ \text { áreas degradadas }\end{array} & \begin{array}{l}\text { Estudos especiais para obras } \\ \text { lineares }\end{array} \\ & & \\ \begin{array}{l}\text { Lançamento de } \\ \text { esgotos }\end{array} & \begin{array}{l}\text { Infra-estrutura } \\ \text { de pesca, turismo }\end{array} & \begin{array}{l}\text { Estudos especiais para } \\ \text { implantação de infra-estrutura } \\ \text { Terraplanagem }\end{array} \\ \begin{array}{ll}\text { e lazer } \\ \text { Educação ambiental } \\ \text { Preservação }\end{array} & \\ & & \end{array}$




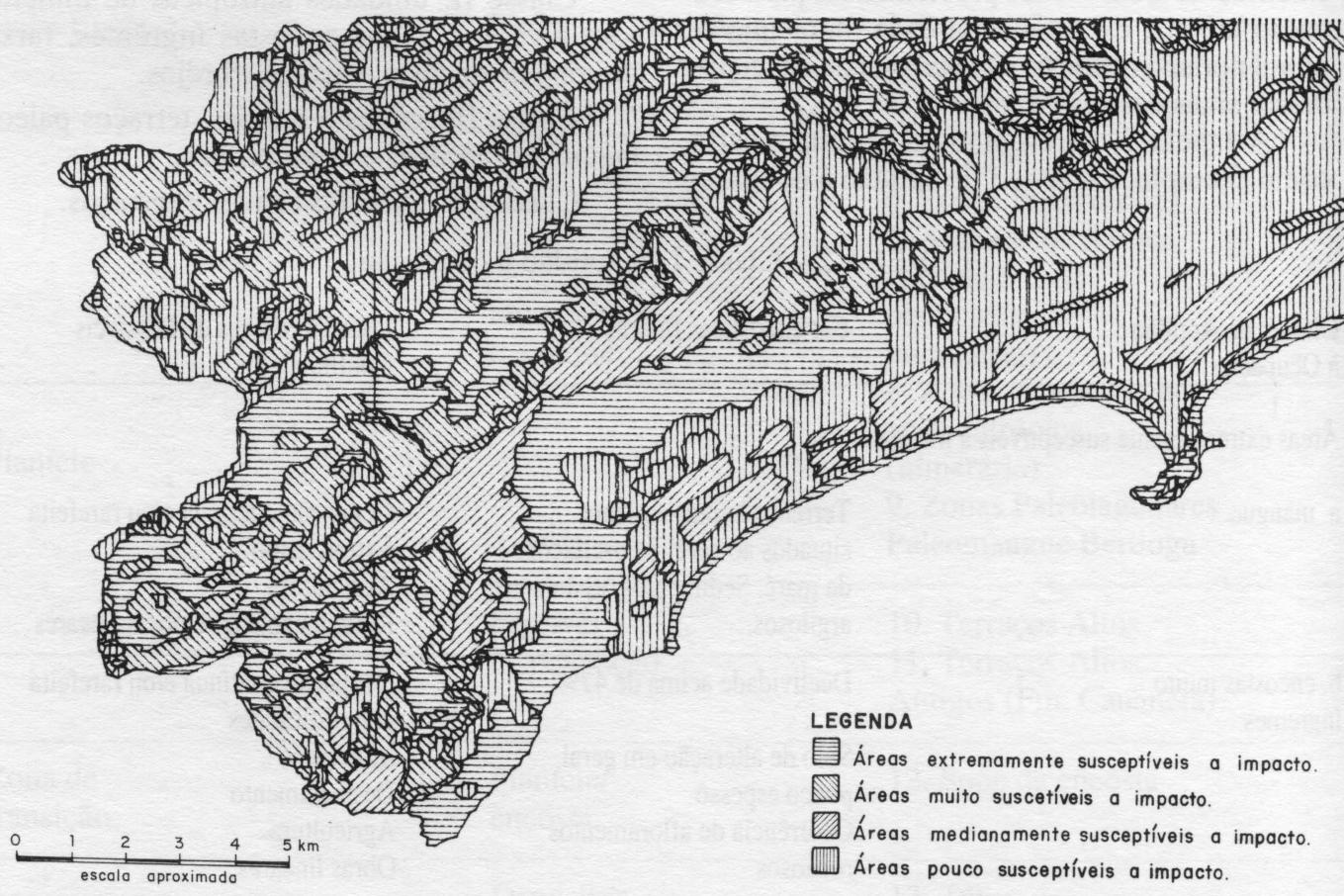

FIGURA 4 - Classes de Aptidão - Folha Bertioga.

As classes de aptidão à ocupação foram delimitadas e cartografadas conforme exemplo mostrado na figura 4 - Classes de aptidão Folha de Bertioga.

\section{CONSIDERAÇÕES FINAIS}

O trabalho do macrozoneamento, na sua magnitude, deverá resultar da análise que considere as restrições impostas pelo meio físico e aquelas determinadas pelas bases legais que sustentam as unidades de conservação e a questão paisagística. A interação desses aspectos com as características atuais e tendências de expansão do uso do solo, no litoral norte, permitirá a demarcação cartográfica de unidades diferenciadas de forma a:

a) prever o desempenho da interação entre a ocupação e o meio físico, bem como os próprios conflitos entre as diversas formas de uso territorial; e

b) orientar medidas preventivas e corretivas, no sentido de minimizar custos e riscos no empreendimento de ocupação do solo.

Quanto à Carta Geotécnica em si, foram detectadas, nos estudos já executados, lacunas de dados importantes para a obtenção final satisfatória do macrozoneamento, tais como estudos de corrida de massa e de dinâmica costeira. Esses estudos, já iniciados, promoverão um melhor balizamento de ações que evitem impactos ambientais e geração de situações de risco à população local.

A aplicação da Carta Geotécnica e das suas correspondentes classes de aptidão deverá sofrer uma discussão pública com os municípios das cidades litorâneas, para sua total compreensão e assimilação e servirá como subsídio técnico para a formulação de decretos que ordenem as diversas atividades de utilização do território na sua faixa costeira, compondo a lei de gerenciamento costeiro. A utilização de dados técnicos, como cartas geotécnicas, subsidiando e orientando a formulação de leis, é um passo que deve ser incentivado e apoiado, evitando-se, assim, desvios de interpretação e incorreções de julgamento, que restringem a melhoria da qualidade de vida das populações em geral. 


\section{BIBLIOGRAFIA CONSULTADA}

LOPEZ, A.G., BARROS, M.O. 1992. Cartografia Geológica Geotécnica do litoral norte do Estado de São Paulo. In: CONGRESSO BRASILEIRO DE GEOLOGIA, 37-, São Paulo, SP, Boletim de resumos expandidos, São Paulo, SP. Sociedade Brasileira de Geologia, V.1.Simpósios, p.47.

\section{BIBLIOGRAFIA CONSULTADA}

FREITAS, C.G.L.; PRANDINI, F.L.; FARAH, F. 1992. Cartografia Geotécnica no litoral paulista. (Trabalho apresentado no I SEMINÁRIO INTERNACIONAL
SOBRE PROBLEMAS AMBIENTAIS DOS GRANDES CENTROS URBANOS. - URBS'92, Rio de Janeiro, 24-29 maio, 1992)

IPT 1991. Carta Geotécnica do município de Ubatuba - SP. São Paulo, (IPT-Relatório $\mathrm{n}^{\circ}$ 28.975. Cliente: SCTDE)

PRANDINI, F.L.; NAKAZAWA, V.A.; FREITAS, C.G.L. 1991. Cartografia Geotécnica nos planos diretores regionais e municipais. São Paulo (IPT 1991, Apostila do Curso de Geologia de Engenharia Aplicada a Problemas Ambientais)

Endereço dos autores: - Álvaro Gutierrez Lopez - DTRR/CETESB - Av. Prof. Frederico Herman Jr., 345, Alto de Pinheiros - 05489-900 São Paulo, SP - Brasil.

- Carlos Geraldo Luz de Freitas - DIGEO/IPT - Av. Prof. Armando Salles Oliveira, Butantã - 05508-901 - São Paulo, SP - Brasil.

- Mariângela Oliveira de Barros e Sidnei Tadeu Rodrigues - Secretaria do Meio Ambiente - DPL/CPLA - Rua Tabapuã, 81, Itaim Bibi 04533-010 - São Paulo, SP - Brasil. 